research

\title{
GLP1- and GIP-producing cells rarely overlap and differ by bombesin receptor-2 expression and responsiveness
}

\author{
Berit Svendsen ${ }^{1,2}$, Ramona Pais ${ }^{3}$, Maja S Engelstoft ${ }^{1,4}$, Nikolay B Milev ${ }^{3}$, Paul Richards ${ }^{3}$, \\ Charlotte B Christiansen ${ }^{1,2}$, Kristoffer L Egerod ${ }^{1,4}$, Signe M Jensen ${ }^{1,3}$, Abdella M Habib ${ }^{3}$, \\ Fiona M Gribble ${ }^{3}$, Thue W Schwartz ${ }^{1,4}$, Frank Reimann ${ }^{3}$ and Jens J Holst ${ }^{1,2}$ \\ ${ }^{1}$ Novo Nordisk Foundation Center for Basic Metabolic Research, University of Copenhagen, Blegdamsvej 3b, \\ 2200 Copenhagen, Denmark \\ ${ }^{2}$ Department of Biomedical Sciences, Faculty of Health and Medical Sciences, University of Copenhagen, \\ Copenhagen, Denmark \\ ${ }^{3}$ Wellcome Trust - MRC Institute of Metabolic Science, University of Cambridge, Cambridge, UK \\ ${ }^{4}$ Department of Neuroscience and Pharmacology, University of Copenhagen, Copenhagen, Denmark
}

Correspondence should be addressed to B Svendsen

Email

bsvendsen@sund.ku.dk

\begin{abstract}
The incretin hormones glucagon-like peptide-1 (GLP1) and glucose-dependent insulinotropic polypeptide (GIP) are secreted from intestinal endocrine cells, the so-called L- and $\mathrm{K}$-cells. The cells are derived from a common precursor and are highly related, and co-expression of the two hormones in so-called L/K-cells has been reported. To investigate the relationship between the GLP1- and GIP-producing cells more closely, we generated a transgenic mouse model expressing a fluorescent marker in GIP-positive cells. In combination with a mouse strain with fluorescent GLP1 cells, we were able to estimate the overlap between the two cell types. Furthermore, we used primary cultured intestinal cells and isolated perfused mouse intestine to measure the secretion of GIP and GLP1 in response to different stimuli. Overlapping GLP1 and GIP cells were rare $(\sim 5 \%) . \mathrm{KCl}$, glucose and forskolin + IBMX increased the secretion of both GLP1 and GIP, whereas bombesin/ neuromedin C only stimulated GLP1 secretion. Expression analysis showed high expression of the bombesin 2 receptor in GLP1 positive cells, but no expression in GIP-positive cells. These data indicate both expressional and functional differences between the GLP1-producing 'L-cell' and the GIP-producing 'K-cell'.
\end{abstract}

Key Words

Journal of Endocrinology (2016) 228, 39-48

\section{Introduction}

The incretin hormones, glucagon-like peptide-1 (GLP1) and glucose-dependent insulinotropic polypeptide (GIP) strongly potentiate postprandial insulin secretion and are therefore important regulators of glucose homeostasis. They are secreted from so-called enteroendocrine L- and K-cells of the intestinal mucosal epithelium. Traditionally,
K-cells have been described to be primarily located in the proximal small intestine, whereas GLP1-producing L-cells are located more distally in the small intestine and colon (Sjolund et al. 1983, Eissele et al. 1992), but a recent study showed that similar amounts of GLP1 are secreted from the proximal and distal small intestine (Svendsen et al.

Published by Bioscientifica Ltd 
2015). In addition, immunohistochemical studies have indicated that there may be co-localisation of the two hormones in endocrine cells of the proximal gut (Mortensen et al. 2003, Theodorakis et al. 2006), and cells isolated on the basis of their production of one of the hormones often show co-expression of the other hormones (Egerod et al. 2012, Habib et al. 2012, Sykaras et al. 2014). Furthermore, a transgenic mouse model with diphtheria toxin-induced knockdown of proglucagonproducing cells showed reduced number of GLP1 positive as well as GIP positive cells (Egerod et al. 2012). Comparisons of expression profiles have indicated that proximal L-cells (defined as cells producing proglucagonderived peptides) are more similar to K-cells than to the distal L-cells (Habib et al. 2012). On the other hand, another study showed that knocking down proglucagonproducing cells with diphtheria toxin in transgenic mice resulted in decreased expression of proglucagon, cholecystokinin (CCK), neurotensin and peptide YY (PYY), but no change in GIP expression. Likewise, knockdown of proGIP did not decrease GLP1 expression (Pedersen et al. 2013). Furthermore, a recent immunohistochemical study in rats showed co-localisation of GIP and GLP1 in only $\sim 10 \%$ of GLP1-producing cells (Svendsen et al. 2015). Previous studies employing several experimental models including single $\mathrm{K}$ - and L-cells have shown that the hormones are secreted in response, for example, to glucose, which after entry via the sodium-glucose transporter-1 results in membrane depolarization and exocytosis secondary to calcium influx in both cell types (Reimann et al. 2008, Parker et al. 2009). Other studies have shown that stimuli activating the cAMP system may also result in both GLP1 and GIP secretion (Simpson et al. 2007, Moss et al. 2012, Hauge et al. 2014, Svendsen et al. 2015).

In order to further investigate the relationship between GLP1- and GIP-secreting cells, we now decided to investigate colocalization using transgenic mice in which GIP and GLP1 cells express different fluorescent markers. In addition, we used several experimental models to investigate the presence or absence of co-secretion of the two hormones, including single cells isolated from transgenic mice in which GLP1- and GIP-producing cells can be identified on the basis of their expression of cell markers under the control of the proGIP or proglucagon promoters, as well as isolated intestinal crypts and isolated perfused proximal mouse small intestine. Mice were chosen to allow comparisons between the models. If the chosen stimuli invariably stimulated the secretion of both hormones, this would provide a strong support for a functional similarity and developmental relationship between $\mathrm{K}$ - and L-cells. It could arise by simultaneous secretion from two separate cell types, or might suggest some degree of co-expression of either hormone from two otherwise distinct cell-types, or even from a distinct celltype showing co-expression of both hormones, a so-called $\mathrm{K} / \mathrm{L}$ cell (Theodorakis et al. 2006). The stimuli we used included bombesin, neuromedin $\mathrm{C}, \mathrm{KCl}$, glucose and forskolin +3-isobutyl-1-methylxanthine (IBMX). Because the results suggested differential responses to bombesin and neuromedin $\mathrm{C}$, we mapped the expression of bombesin (BB) receptors (1-3) in single cells isolated on the basis of fluorescent markers expressed under the control of GLP1 or GIP promoters (Habib et al. 2012).

\section{Materials and methods}

\section{Primary small intestinal crypt culture}

All animal procedures were approved by local ethical review committees and conformed to UK Home Office regulations. Three- to six-month-old C57B6 male and female mice weighing 25-30 g were used in the study. They were housed in groups of 3-5/cage in a SPFmaintained facility and had ad libitum access to food and drinking water. Small intestinal crypts were isolated and cultured as previously described (Reimann et al. 2008). In summary, mice were killed by cervical dislocation and the duodenum $(10 \mathrm{~cm}$ distal to the stomach) was excised. Luminal contents were flushed thoroughly with PBS and the outer muscle layer removed. Tissue was minced and digested with Collagenase Type XI and the cell suspension plated onto Matrigel (BD Bioscience, Oxford, UK) precoated 24-well plates for GLP1 and GIP secretion experiments or on $35 \mathrm{~mm}$ glass bottomed dishes (MatTek Corporation, Ashland, MA, USA) for calcium imaging.

\section{GLP1 and GIP secretion assay}

Eighteen to $24 \mathrm{~h}$ after plating, cells were washed and incubated for $2 \mathrm{~h}$ with or without bombesin (100 nM) and glucose $(10 \mathrm{mM})$. Test agents made up in saline buffer (in mM $138 \mathrm{NaCl}, 4.5 \mathrm{KCl}, 4.2 \mathrm{NaHCO}_{3}, 1.2 \mathrm{NaH}_{2} \mathrm{PO}_{4}, 2.6$ $\mathrm{CaCl}_{2}, 1.2 \mathrm{MgCl}_{2}$, and 10 HEPES, pH adjusted to 7.4 with $\mathrm{NaOH}$ ) supplemented with $0.1 \% \mathrm{BSA}$ for $2 \mathrm{~h}$ at $37^{\circ} \mathrm{C}$. At the end of the 2-h incubation, supernatants were collected and centrifuged at $2000 \boldsymbol{g}$ for $5 \mathrm{~min}$ and snap-frozen on dry ice. Cells were lysed with lysis buffer and centrifuged at $10000 \boldsymbol{g}$ for $10 \mathrm{~min}$ and snap-frozen. GLP1 and GIP concentrations were assayed in supernatant

Published by Bioscientifica Ltd. 
fractions and cell extracts from primary intestinal cultures using a total GLP1 assay (Meso Scale Discovery, Gaithersburg, MD, USA) and GIP Total ELISA kit (Millipore, Billerica, MA, USA). Each test agent was tested in three or four wells per 24-well plate on four cultures independently established from one mouse each. Results were expressed as a percentage of the total hormone content (secreted+lysate) per well. Hormone secretion was compared with baseline or between conditions by ANOVA with subsequent Bonferroni's test.

\section{Transgenic mouse models}

Transgenic mice were generated and bred in Cambridge with the approval of the Local Ethical Review Committee and in accordance with UK Home Office guidelines. K- and L-cells for transcriptomic analysis were purified from GIPVenus and GLU-Venus strains (Reimann et al. 2008, Parker et al. 2009). For calcium imaging, transgenic mice were engineered to express the fluorescence-based calcium sensor GCaMP3 in either L- or K-cells. L-cell specificity was achieved by crossing the GLU-Cre strain with ROSA26-GCaMP3 (Parker et al. 2012).

To label K-cells, we generated a new mouse strain GIP-Cre. To express Cre-recombinase iCre (a kind gift from Rolf Sprengel) under the control of the gip promoter, we replaced the sequence between the gip start codon in exon 2 and stop codon in exon 6 in the murine-based bacterial artificial chromosome (BAC) RP24-298N3 (mouse based) (Children's Hospital Oakland Research Institute) by the iCre sequence using Red/ET recombination technology (GeneBridges). In summary, iCre sequence was amplified by PCR adding gip gene-specific $3^{\prime}$ and $5^{\prime}$ sequences and homologous recombination was achieved upon co-transforming an rpsLneo-modified BAC containing E. coli DH10B clone with the PCR product and the plasmid pSC101-BAD-gbaA, which provides the recombination enzymes (GeneBridges). Positive recombinants were isolated using appropriate antibiotic selection and characterised by PCR and restriction analysis. Identity and correct positioning of the introduced iCre sequence were confirmed by Sanger sequencing. BAC-DNA for microinjection was purified using the large-construct Maxi-Prep kit (Qiagen) and dissolved at $\sim 1-2 \mathrm{ng} / \mu \mathrm{l}$ in injection buffer containing (mmol/l) 10 Tris-HCl pH 7.5, 0.1 EDTA, $100 \mathrm{NaCl}, 0.03$ spermine and 0.07 spermidine. Pronuclear injection into ova derived from C57B6/CBA F1 parents and re-implantation of embryos into pseudo-pregnant females was performed by the Central Biomedical Services at Cambridge University. DNA of pups was isolated from ear clips by proteinase $\mathrm{K}$ digestion and screened for the transgene by PCR using primer pairs against gip, iCre, reporter genes and beta-catenin, which served as a DNA quality control. Mice were back-crossed into C57B6 for at least seven generations. We initially received three founders (mGIP-Cre-117, -122 and -125), all of which faithfully passed on the transgene (estimated transgene copy numbers were $1 ; 1$ and 2) in a Mendelian fashion with no gender bias. mGIP-Cre-117 was used in all experiments, and is referred to hereon as GIP-Cre.

\section{Flow cytometry}

The upper small intestine $(10 \mathrm{~cm}$ distal to the gastric pylorus) of GIP-Cre/ROSA26-RFP mice was stripped of the muscle layer and digested to single cells using $1 \mathrm{mg} / \mathrm{ml}$ collagenase XI in calcium free-Hanks' buffered salt solution. Cell suspensions were fixed using $4 \%$ paraformaldehyde in PBS for 15-30 min at room temperature, permeabilised with $0.1 \% \mathrm{v} / \mathrm{v}$ Triton X-100 for $30 \mathrm{~min}$ at room temperature, blocked with $10 \%$ goat serum in PBS for $30 \mathrm{~min}$, and incubated with primary antibody (GLP; Santa Cruz; sc-13091; 1:200. GIP; antiserum \#80867 from JJ Holst (Lindgren et al. 2011); 1:1000) in PBS-10\% goat serum at room temperature for $3 \mathrm{~h}$.

Cells were rinsed $\times 3$ in PBS and then incubated with secondary antibody (Alexa-Fluor 488, Invitrogen; 1:300). After three washes with PBS, cells were analysed using a five-laser LSRFortessa analyser (BD Biosciences, San Jose, CA, USA) and FlowJo 7.6 software (Ashland, OR, USA). Events with very low side and forward scatter or with high pulse width were excluded to eliminate debris and cell aggregates. Presented mean data is the average from three to seven independent preparations, with each preparation derived from a different mouse.

\section{Immunohistochemistry}

Freshly dissected intestines from GIP-Cre/ROSA26GCaMP3 mice $(n=3)$ were cleaned using PBS and dropped into $4 \%$ paraformaldehyde in PBS and left at $4{ }^{\circ} \mathrm{C}$ to fixate overnight. The intestines were dehydrated in 15 and 30\% sucrose solutions and frozen in OCT embedding media (CellPath, UK). Cryostat-cut sections $(10-12 \mu \mathrm{m})$ were mounted directly onto poly-lysine covered glass slides.

The sections were incubated with a blocking solution of PBS containing 10\% donkey serum, $0.1 \%$ BSA and 0.05\% Tween20 (VWR, Lutterworth, UK) for $1 \mathrm{~h}$. Blocking solution was replaced with $10 \%$-PBS serum solution with $0.1 \%$ BSA and primary antibodies (GIP; as used for flow cytometry. GFP; Abcam, Cambridge, UK; Ab5450; 1:1000)

Published by Bioscientifica Ltd 
and left overnight. The following day, the slides were rinsed three times in PBS and incubated with a 10\%-PBS serum solution containing secondary antibodies (Alexa-Fluor 488 and 555; Invitrogen; 1:300) and Hoechst diluted to 1:1300, for $1 \mathrm{~h}$. The sections were rinsed three times in PBS to remove unconjugated antibodies. All slides were mounted with Prolong Gold (Life Technologies, Paisley, UK) prior to confocal microscopy on a Zeiss LSM510. Control slides were stained with secondary antibodies only.

\section{Calcium imaging}

Intracellular calcium concentrations were monitored from crypt cultures prepared from the duodenum of GLU-Cre/ROSA26-GCaMP3/ROSA26-tdRFP or GIP-Cre/ ROSA26-GCaMP3/ROSA26-tdRFP mice. K- and L-cells were identified by Red Fluorescent Protein (RFP) fluorescence and changes in intracellular calcium levels were represented by a change in the intensity of GCaMP3 fluorescence excited at $488 \pm 10 \mathrm{nM}$. Imaging was performed using an Olympus IX71 microscope with a $40 \times$ oil immersion objective, fitted with a monochromator (Cairn Research, Kent, UK) and OrcaER camera (Hamamatsu, Shizuoka, Japan). Images were acquired at $1 \mathrm{~Hz}$ and analysed, after background subtraction, using MetaFluor software (Molecular Devices, Sunnyvale, CA, USA). Solutions were perfused continuously at a rate of $\sim 1 \mathrm{ml} / \mathrm{min}$ and responses to test reagents were calculated by determining the mean intensity at $488 \mathrm{~nm}$ during perfusion of the test reagent divided by the average of the baseline 488 intensity taken before and after test reagent application. Test reagents were tested on 10-20 individual cells from four independent crypt cultures established from four GIP-Cre and four GLU-Cre mice respectively.

\section{The perfused mouse intestine}

Eight male C57BL/6J mice (10 weeks, purchased from Taconic, Denmark) were used for perfusion of the proximal intestine. The perfusion experiments conformed to international guidelines and were approved by the Animal Experiments Inspectorate, Ministry of Justice, Denmark. Animals were housed five animals to a each cage and kept on a ratio of $12 \mathrm{~h}$ light: $12 \mathrm{~h}$ darkness cycle with free access to standard rat chow and water, and allowed to acclimatize for 1 week before use. The animals were anaesthetized with i.p. injection of ketamine/ xylazine (Ketamine $90 \mathrm{mg} / \mathrm{kg}$ (Ketaminol Vet.; MSD Animal Health, Madison, NJ, USA) + Xylazine $10 \mathrm{mg} / \mathrm{kg}$ (Rompun Vet.; Bayer Animal Health, Leverkusen,
Germany). A catheter $(0.7 \mathrm{~mm})$ was placed in the aorta for inflow of the perfusion medium and perfusion of the intestine via the superior mesenteric artery at a flow rate of $2.2 \mathrm{ml} / \mathrm{min}$. The stomach, kidneys, spleen, colon and distal small intestine were tied off and removed to prevent perfusion, thus only the proximal small intestine was perfused $(\sim 10 \mathrm{~cm})$. The venous effluent was collected in 1-min periods via a catheter $(0.9 \mathrm{~mm})$ inserted into the portal vein, now exclusively draining the perfused segment. The intestinal lumen was perfused with $37^{\circ} \mathrm{C}$ saline at a flow rate of $0.04 \mathrm{ml} / \mathrm{min}$.

The perfusion medium (a modified Krebs Ringer bicarbonate buffer containing, in addition, $0.1 \%$ BSA (Merck KGaA), 5\% Dextran T-70 (Dextran Products Limited, Scarborough, Canada), $3.5 \mathrm{mmol} / \mathrm{l}$ glucose, and $5 \mathrm{mmol} / \mathrm{l}$ of each of pyruvate, fumarate, and glutamate) was gassed with a $95 \% \mathrm{O}_{2} / 5 \% \mathrm{CO}_{2}$ mixture to achieve $\mathrm{pH}$ 7.3-7.4 and maintained at $37^{\circ} \mathrm{C}$ during the experiment. Perfusion pressure remained relatively constant throughout each experiment $(\sim 50 \mathrm{mmHg})$. After the intestinal perfusion was established, the animals were exsanguinated and the intestine was allowed to stabilise for $\sim 30 \mathrm{~min}$ before the experiment was started. Test substances included bombesin (10 nM; Bachem), Neuromedin C $(10 \mathrm{nM})$, forskolin $(10 \mu \mathrm{M})+\operatorname{IBMX}(10 \mu \mathrm{M})$, and $\mathrm{KCl}$ $(70 \mathrm{mM})$ infused through a sidearm with a syringe infusion pump $(0.11 \mathrm{ml} / \mathrm{min})$ for $5-10 \mathrm{~min}$ followed by a resting period of $20 \mathrm{~min}$. Chemicals were obtained from Sigma Aldrich, unless otherwise stated. For these experiments, GLP1 concentrations in perfusion effluent samples were measured using RIA (antiserum \#89390 (Orskov et al. 1994)) and GIP was measured with Millipore total rat GIP ELISA kit according to the manufacturer's instructions. Responses to a given stimulus were analysed by comparing the mean total outputs during the $5 \mathrm{~min}$ and the total output during the $5 \mathrm{~min}$ of infusion, using paired t-tests.

\section{Single cell expression analysis}

Single cell suspensions were prepared from the first $10 \mathrm{~cm}$ of the proximal small intestine from GLU-Venus or GIPVenus mice and separated into fluorescence-positive and fluorescence-negative pools of cells using fluorescenceactivated cell sorting (FACS) as described (Habib et al. 2012). The cells were sorted directly into lysis buffer (Ambion, Thermo Fisher Scientific,Waltham, MA, USA) and the RNA was purified using the RNAqueousMicro micro-scale RNA isolation kit (Ambion, Thermo Fisher Scientific,Waltham, MA, USA). cDNA was prepared using Superscript III (Invitrogen, Thermo Fisher

Published by Bioscientifica Ltd 
Scientific,Waltham, MA, USA). The expression of 379 G protein-coupled receptors was tested using customdesigned 384 well qPCR plates from Lonza. Primer target sequences have been published before (Engelstoft et al. 2013). A genomic DNA sample was used as a calibrator and relative copy numbers were calculated as described by Engelstoft et al. (2013).

\section{Results}

\section{Hormone secretion from primary cultures}

We investigated the secretion of GLP1 and GIP from primary cultures of the upper small intestine (Fig. 1). Cultures were incubated for $2 \mathrm{~h}$ in the presence and absence of glucose $(10 \mathrm{mM})$ and bombesin $(100 \mathrm{nM})$, and supernatants and cell extracts were then analysed for their contents of both GLP1 and GIP. Glucose-enhanced secretion of both GLP1 and GIP 2.5 fold (Fig. 1) compared with baseline. Bombesin further increased GLP1 release $\sim 2-2.5$ fold in the absence of glucose, and $\sim 1.5$ fold in the presence of glucose. GIP release was unaffected by bombesin under either condition.
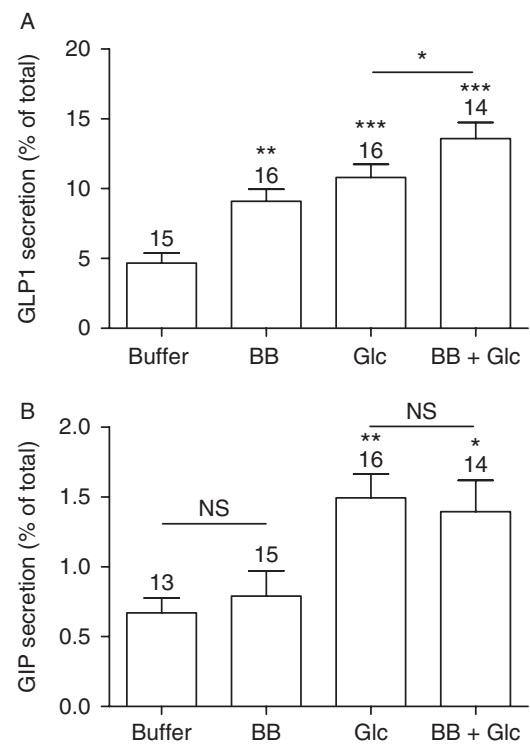

Figure 1

GLP1 and GIP secretion from primary murine duodenal cultures. Mixed epithelial cultures established from the top $10 \mathrm{~cm}$ of the small intestine in 24 well plates were incubated for $2 \mathrm{~h}$ with or without bombesin (BB; $100 \mathrm{nM}$ ) and glucose (Glc; $10 \mathrm{mM}$ ) as indicated. GLP1 (A) and GIP (B) contents of the supernatant and cell lysates were measured, and results calculated as a percentage of the hormone content (secreted plus intracellular) per well. Data are from four independent cultures established from one mouse each and represent the mean and S.E.M. of the number of wells indicated above each bar. ${ }^{*} P<0.05, * * P<0.01$ and $* * * P<0.001$ compared with baseline, or between conditions.

\section{Low overlap of L- and K-cells in transgenic mouse models}

As the secretion results suggested that GIP and GLP1 secretion are regulated differentially, we generated a new transgenic mouse model GIP-Cre to label K-cells with fluorescent markers or reporters of intracellular signalling events (Fig. 2). Upper small intestinal cell suspensions from GIP-Cre/ROSA26-tdRFP mice were immunostained for GIP and GLP, and analysed by flow cytometry to determine the cell specificity of K-cell labelling and the overlap between K- and L-cells. GIP staining was detected in $>90 \%$ of tdRFP-labelled cells, confirming the K-cell specificity of Cre expression. The proportion of GIPstained cells that were labelled with the fluorescent reporter was $\sim 60 \%$ in this model, compared with $\sim 30 \%$ in GIP-Venus mice (Fig. 2). Only $\sim 5 \%$ of tdRFP positive cells in GIP-Cre/ROSA26-tdRFP mice stained for GLP, indicating only a limited overlap of $\mathrm{K}$ - and L-cell populations.

\section{Calcium responses in primary L- and K-cells}

To monitor intracellular $\mathrm{Ca}^{2+}$ in identified primary upper small intestinal L- and K-cells, we crossed the ROSA26GCaMP3 reporter mouse with either GLU-Cre (expressing cre recombinase under proglucagon promoter control) or GIP-Cre mouse strains. L-cells (Fig. 3A and B) showed robust elevations of GCaMP3 fluorescence in response to $100 \mathrm{nM}$ bombesin, $10 \mathrm{mM}$ glucose and $70 \mathrm{mM} \mathrm{KCl}$, indicative of an elevation of intracellular $\mathrm{Ca}^{2+}$ with all three stimuli, and consistent with previous reports that bombesin receptor $2\left(\mathrm{BB}_{2}\right.$; GRP-receptor) activation recruits $\mathrm{G}_{\mathrm{q}}$ proteins, triggering $\mathrm{Ca}^{2+}$ release from intracellular stores. K-cells (Fig. 3C and D) exhibited good responses to glucose and $\mathrm{KCl}$, but did not respond to bombesin, mirroring the absence of bombesin-triggered GIP secretion in both perfused intestine and primary cultures.

\section{Hormone secretion from perfused mouse small intestine}

We next investigated whether the secretion results from the primary cultures were mirrored in secretion studies performed on the perfused mouse small intestine (Fig. 4). GLP1 secretion from the perfused proximal small intestine was significantly increased by vascular infusion of both bombesin (from $92 \pm 14$ to $493 \pm 59 \mathrm{fmol} / 5 \mathrm{~min}$; 5.7 fold; $P<0.01)$ and neuromedin C $(114 \pm 40$ to $467 \pm$ $7 \mathrm{fmol} / 5 \mathrm{~min}$; 5.1 fold; $P<0.05)$, as well as forskolin + IBMX (from $162 \pm 19$ to $505 \pm 80 \mathrm{fmol} / 5 \mathrm{~min}$; 3.1 fold;

Published by Bioscientifica Ltd. 


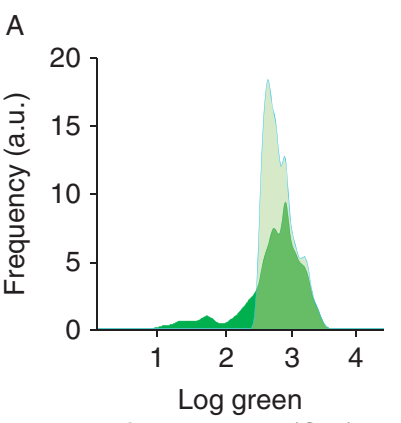

fluorescence (GIP)

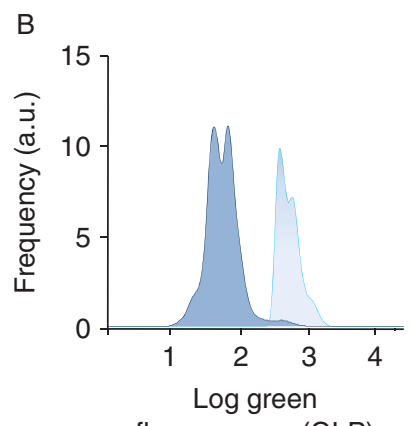

fluorescence (GLP)
C

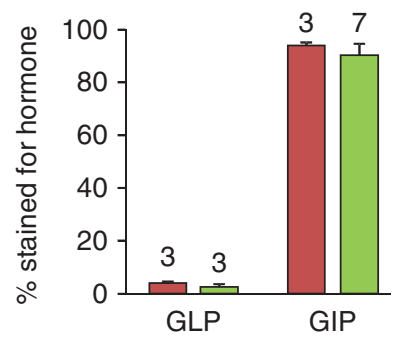

D

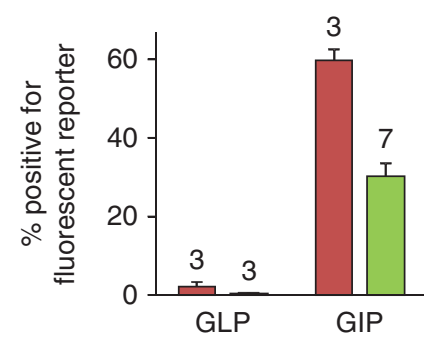

E

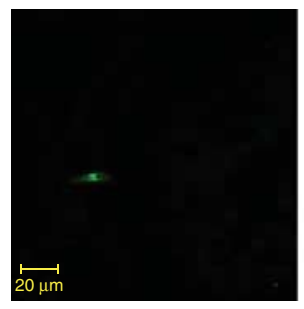

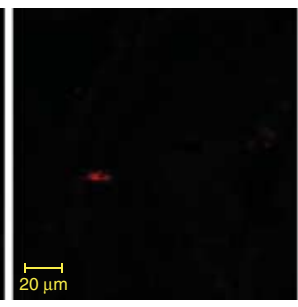
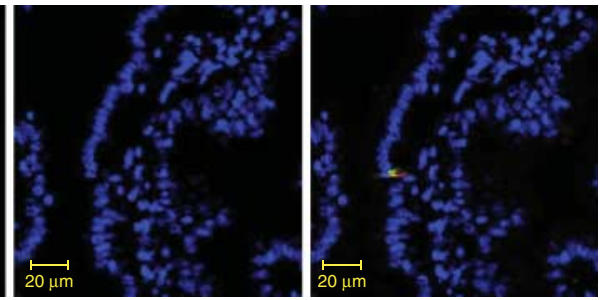

Figure 2

Characterisation of GIP-Cre/ROSA26-tdRFP mice. Single-cell suspensions from the upper small intestine of GIP-Cre/ROSA26-RFP mice were stained with antibodies against GIP (A) or GLP (B) and a green secondary and analysed by FACS. Frequency histograms represent the green fluorescence of all RFP-positive cells (dark shading) or all strongly green fluorescent cells (light shading). $Y$-axes represent frequency of cell detection on an arbitrary scale. (C) Mean data from experiments performed as in panels A and B, representing the percentage of RFP-positive cells that stained positive for GIP or GLP (red bars). Results obtained from GIP-Venus mouse are also

$P<0.05)$ and $\mathrm{KCl}(113 \pm 6$ to $433 \pm 92 \mathrm{fmol} / 5 \mathrm{~min} ; 4.0$ fold; $P<0.05)$. Secretion of GIP was increased by infusion of forskolin +IBMX $(39 \pm 9$ to $129 \pm 32 \mathrm{fmol} / 5 \mathrm{~min} ; 3.6$ fold; $P<0.05)$ and $\mathrm{KCl}(77 \pm 2$ to $249 \pm 62 \mathrm{fmol} / 5 \mathrm{~min}$; shown for comparison (green bars). (D) Mean data from experiments performed as in panels $A$ and $B$, representing the percentage of green fluorescent (antibody stained) cells that were also positive for RFP (red bars). GIP-Venus data are presented alongside as a comparator (green bars). Data represent mean \pm S.E.M. of the number of preparations indicated. (E) Intestines taken from GIP-Cre/ROSA26-GCaMP3 mice $(n=3)$ were fixed, sectioned and stained with antibodies against GIP (red) and GFP (green). A representative image of a double positive cell located in the duodenum is shown.

2.9 fold; P0.05) but no significant effect was observed after infusion of either bombesin $(27 \pm 4$ to $44 \pm$ $4 \mathrm{fmol} / 5 \mathrm{~min})$ or neuromedin $\mathrm{C}(87 \pm 21$ to $118 \pm$ $14 \mathrm{fmol} / 5 \mathrm{~min}$ ) (Fig. 4).
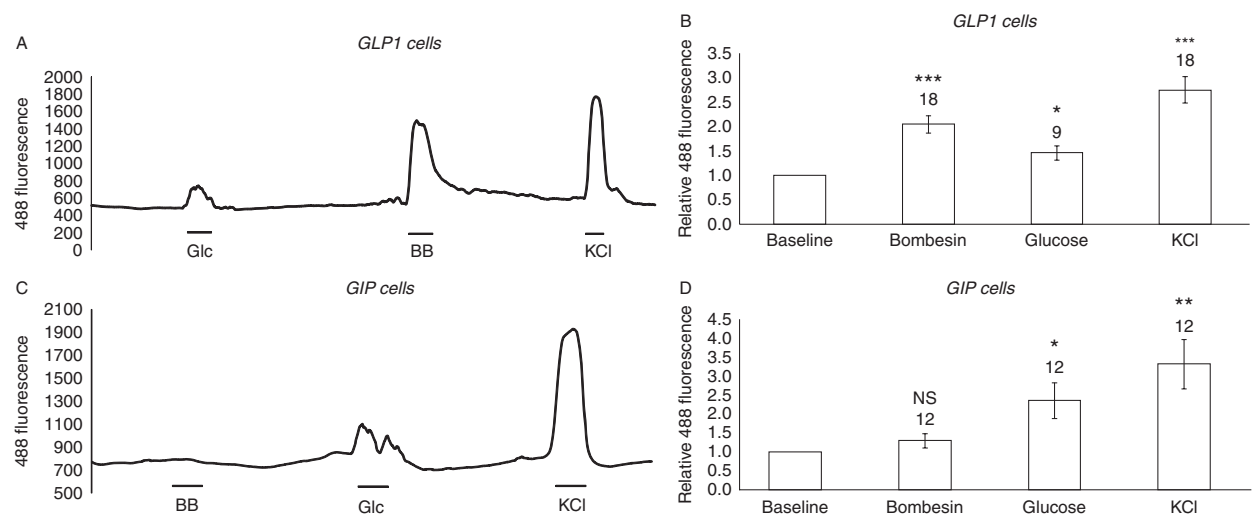

Figure 3

$\left[\mathrm{Ca}^{2+}\right]$ imaging in mouse primary duodenal L-cells and K-cells. GFP fluorescence (reflecting $\left[\mathrm{Ca}^{2+}\right]_{\mathrm{i}}$ ) was utilized to record changes in intracellular $\left[\mathrm{Ca}^{2+}\right]$ changes following the addition of $100 \mathrm{nM}$ bombesin (BB), $10 \mathrm{mM}$ Glucose (Glc) and $70 \mathrm{mM} \mathrm{KCl}$. (A) and (C) Representative trace showing the change in GCaMP3 fluorescence before, during and after the application to a primary duodenal GLP1 cell cultured from GLU-Cre/
ROSA26-GCaMP3 mice (A) or a primary duodenal GIP cell cultured from GIPCre/ROSA26-GCaMP3mice (C). (B) and (D) GFP intensity in the presence of the test agent was normalised to the mean background of each cell measured pre and post application of the test compound in GLP1 cells (B) and GIP cells (D). Data represent the mean and S.E.M. of the number of cells indicated above each bar. ${ }^{*} P<0.05, * * P<0.01, * * * P<0.001$ compared with baseline.

Published by Bioscientifica Ltd. 
A

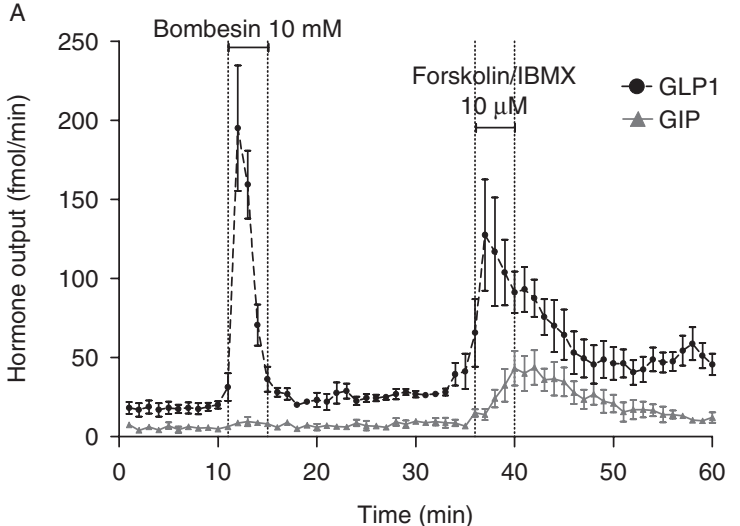

C

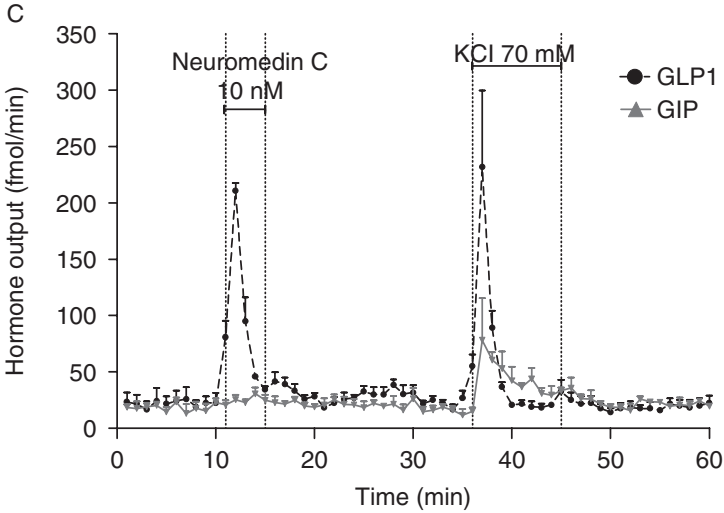

Figure 4

Secretion of GLP1 and GIP from the perfused mouse proximal small intestine. The intestine was stimulated with vascular infusion of $(A)$ and (B) bombesin $(10 \mathrm{nM})$ and forskolin/IBMX $(10 \mu \mathrm{M})$; and (C) and (D) neuromedin

\section{Expression}

GIP-venus and GLP1-venus positive cells were FACS-purified from single-cell preparations of mucosal cells generated from the proximal small intestine of transgenic GIP-venus (Parker et al. 2009) or GLU-venus reporter mice (Reimann et al. 2008). cDNA from the purified cell populations was analysed for bombesin receptor expression by a qPCR array targeting 379 non-odorant 7TM receptors (Fig. 5) as previously reported (Panaro et al. 2014). None of the three bombesin receptors was expressed above background levels in GIP cells (Fig. 5A). In contrast, the $\mathrm{BB}_{2}$ receptor was expressed in GLP1 cells - as the only one of the bombesin receptors (Fig. 5B). Grpr mRNA was enriched 37-fold in the GLP1 cells compared to the surrounding epithelial cells.

\section{Discussion}

In this study, we tried to analyze more closely the relationship between the cells secreting the two incretin hormones GIP and GLP1, by investigating both
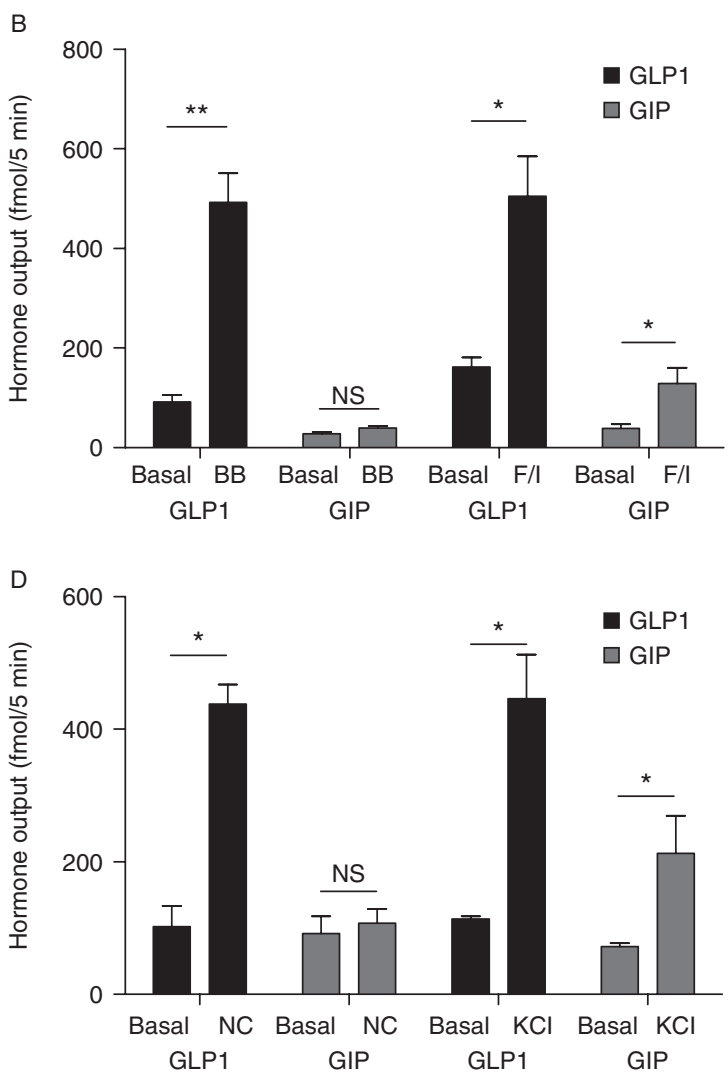

$\mathrm{C}(10 \mathrm{nM})$ and $\mathrm{KCl}(70 \mathrm{mM})$. (B) and (D) Total hormone outputs from $5 \mathrm{~min}$ before and during infusion of test substances are compared; mean \pm s.E.M., $n=4 .{ }^{*} P<0.05,{ }^{*} * P<0.01$.

co-localisation and co-secretion of the hormones. As already alluded to, the classical concept has it that the GIP-producing cells are located proximally and the GLP1producing cells more distally, suggesting that GIP is the primary incretin, while GLP1 would function more as an 'ileal brake' hormone, providing a stop signal with respect to appetite and upper gastrointestinal function, as well as facilitating further deposition of already absorbed nutrients. However, the rapid postprandial increase in the plasma concentration of GLP1 generally parallels GIP responses (Knop et al. 2007). Both neural and endocrine mechanisms have been proposed to account for this (Plaisancie et al. 1994, Rocca \& Brubaker 1999, Hansen \& Holst 2002), but a simpler explanation has now been provided with the demonstration that proximal L-cells are capable of providing similar responses to nutritional and other stimuli as those elicited from the distal small intestine (Svendsen et al. 2015). In addition, there is strong evidence that the small intestinal cells may be more closely related and more promiscuous in terms of secretory

Published by Bioscientifica Ltd 

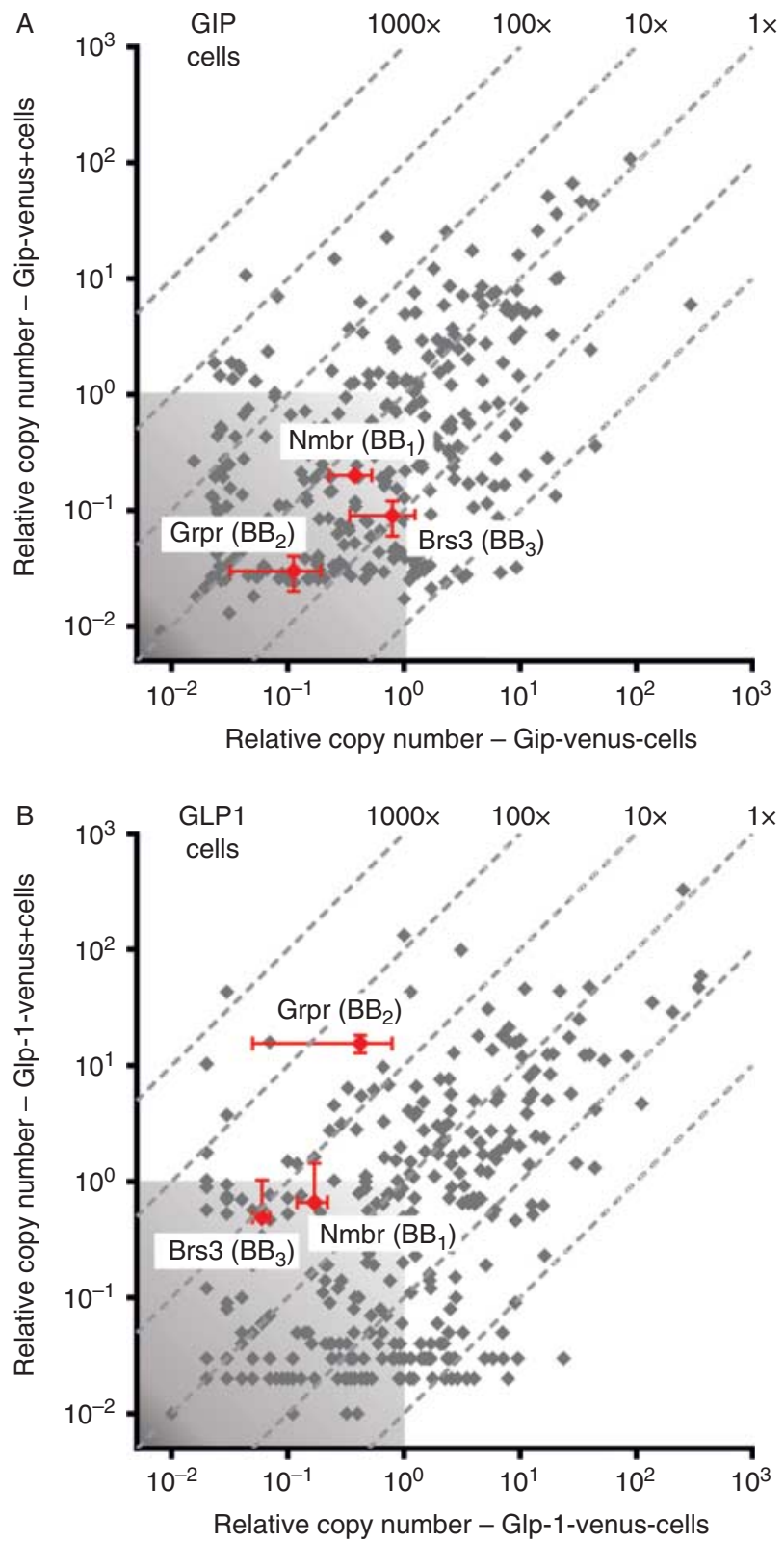

Figure 5

Expression of bombesin receptors in GIP and GLP1 cells. Scatter plots showing qPCR expression of the three bombesin receptors (annotated red dots) among 379 7TM receptors (grey plus red dots) examined in FACS-purified cells from the proximal small intestine from transgenic (A) GIP-Venus, and (B) GLP1-Venus reporter mice ( $Y$-axis) vs expression in non-fluorescent mucosal cells ( $X$-axis). The $45^{\circ}$-angled lines indicate the enrichment of expression in the fluorescent FACS-purified enteroendocrine cells vs the neighbouring enterocytes. The grey shaded area in each of the scatter plots is considered as noise level.

products than hitherto believed, showing a high degree of co-expression of several gut hormones (Habib et al. 2012, Egerod et al. 2012, Pedersen et al. 2013, Sykaras et al. 2014). In particular, the relationship between the GIP- and the
GLP1-secreting cells has attracted interest, resulting in proposals that a ' $\mathrm{K} / \mathrm{L}$ ' cell type secreting both hormones might exist (Mortensen et al. 2003, Theodorakis et al. 2006). In this analysis, we examined the simultaneous secretion of GIP and GLP1 from the isolated upper small intestine from mice, using stimuli meant to engage different signalling pathways, namely i) depolarizing concentrations of potassium chloride, expected to cause an opening of calcium channels, thereby providing a secretory stimulus; ii) forskolin/IBMX providing a strong amplification of the cAMP system by stimulating adenylate cyclase and inhibiting cAMP degradation and iii) bombesin and neuromedin $\mathrm{C}$, agents that via activation of Gq would increase intracellular calcium concentrations by mobilising intracellular depots in response to inositol trisphosphate (IP3) signalling (Snow et al. 1994). In addition to studying the secretion of the hormones from the integrated but isolated endocrine organ, the gut, capable of responding in a manner identical to that expected in the intact animal in vivo, we were able to study the responses of primary cultured enteroendocrine cells with active promoters for either proGIP or proglucagon (i.e., GIP- and GLP1-producing cells) identified and isolated on the basis of this promoter activity. For the secretion experiments, we found it essential to study mice, since the studies regarding the 'promiscuity' of the gut endocrine cells and the primary cell studies were all performed in mice. This required the development of a procedure for isolating and perfusing the mouse upper small intestine, which turned out to be feasible on the basis of experience with the perfused rat small intestine (Svendsen et al. 2015). Histological appearance of the perfused segments was completely normal, and measures of respiration and motility patterns all indicated a viable preparation. The findings indicated that GLP1 and GIP secretion were both stimulated by forskolin/IBMX promoting the cAMP pathways and by $\mathrm{KCl}$ depolarization. In contrast, neuromedin $\mathrm{C}$ and bombesin exclusively stimulated the secretion of GLP1. The patterns of secretion also showed differences - in response to $\mathrm{KCl}$, the GLP1 response was short-lived, whereas the GIP response was more prolonged. In the isolated cells, glucose-stimulated secretion from both proglucagon- and proGIP-expressing cells, but bombesin enhanced secretion further only in the proglucagon cells.

Our new mouse model, GIP-Cre, enabled us to reassess the overlap between K- and L-cells and to monitor calcium responses in primary living K-cells. FACS analysis confirmed previous findings from GLU-Venus and GIPVenus mice (Habib et al. 2012) that only a small

Published by Bioscientifica Ltd 
proportion $(<10 \%)$ of K-cells stain positive for GLP1. Also by calcium imaging, it was clear that L-cells, but not K-cells, responded to bombesin, although both cell types exhibited similar responses to $\mathrm{KCl}$ and glucose.

Finally, in the expression profiling studies on isolated cells, it was evident that while the $\mathrm{BB}_{2}$ receptor, thought to be the main target for bombesin and neuromedin $\mathrm{C}$ (i.e., the C-terminal fragment of the neuropeptide, gastrin-releasing peptide) (Erspamer \& Melchiorri 1976), was highly enriched in proglucagonexpressing cells, whereas proGIP cells exhibited a very low expression level.

Taken together, these studies indicate that the secretion of GLP1 and GIP must derive from separate cell types that, probably among other things, at least can be distinguished by their differential expression of the $\mathrm{BB}_{2}$ receptor. The results are consistent with the cell ablation studies that showed that knock-down of one of the two incretin-producing cell types with diphtheria toxin, although accompanied by reduced expression of several other gut hormones, did not influence the expression of the other hormone (Pedersen et al. 2013). The results are also consistent with recent studies in upper rat small intestine where immunohistochemical co-localisation of GLP1 and GIP was a rare phenomenon (Svendsen et al. 2015). Therefore, in spite of many similarities in terms of localisation and function, the GIP cells and the GLP1 cells of the proximal gut of mice seem mainly to be separate entities. Our results imply that co-localisation does not invariably lead to cosecretion of the gut hormones. Rather, mechanisms for release must be characterised for each of the hormones separately.

\section{Declaration of interest}

The authors declare that there is no conflict of interest that could be perceived as prejudicing the impartiality of the research reported.

\section{Funding}

This work was supported by the Novo Nordisk Foundation Center for Basic Metabolic Research as well as the European Union's Seventh Framework Programme for research, technological development and demonstration under grant agreement $n^{\circ} 266408$. M S E is supported by a postdoc fellowship from the Danish Diabetes Academy supported by the Novo Nordisk Foundation. C B C is supported by doctoral fellowships from the Lundbeck Foundation and from the Danish Diabetes Academy supported by the Novo Nordisk Foundation. Work in the Reimann/Gribble laboratories is supported by the Wellcome Trust (WT106262/Z/14/Z and WT106263/Z/14/Z) and the MRC (grant MRC_MC_UU_12012/3).

\section{References}

Egerod KL, Engelstoft MS, Grunddal KV, Nohr MK, Secher A, Sakata I, Pedersen J, Windelov JA, Fuchtbauer EM, Olsen J et al. 2012 A major lineage of enteroendocrine cells coexpress CCK, secretin, GIP, GLP1, PYY, and neurotensin but not somatostatin. Endocrinology 153 5782-5795. (doi:10.1210/en.2012-1595)

Eissele R, Goke R, Willemer S, Harthus HP, Vermeer H, Arnold R \& Goke B 1992 Glucagon-like peptide- 1 cells in the gastrointestinal tract and pancreas of rat, pig and man. European Journal of Clinical Investigation 22 283-291. (doi:10.1111/j.1365-2362.1992.tb01464.x)

Engelstoft MS, Park WM, Sakata I, Kristensen LV, Husted AS, OsborneLawrence S, Piper PK, Walker AK, Pedersen MH, Nohr MK et al. 2013 Seven transmembrane $\mathrm{G}$ protein-coupled receptor repertoire of gastric ghrelin cells. Molecular Metabolism 2 376-392. (doi:10.1016/j.molmet. 2013.08.006)

Erspamer V \& Melchiorri P 1976 Proceedings: Amphibian skin polypeptides active on the gut. Journal of Endocrinology $\mathbf{7 0}$ (Suppl 3) 12P-13P (available at: http://joe.endocrinology-journals.org/content/70/ 3_Suppl.toc)

Habib AM, Richards P, Cairns LS, Rogers GJ, Bannon CA, Parker HE, Morley TC, Yeo GS, Reimann F \& Gribble FM 2012 Overlap of endocrine hormone expression in the mouse intestine revealed by transcriptional profiling and flow cytometry. Endocrinology 153 3054-3065. (doi:10.1210/en.2011-2170)

Hansen L \& Holst JJ 2002 The effects of duodenal peptides on glucagon-like peptide-1 secretion from the ileum. A duodeno-ileal loop? Regulatory Peptides 110 39-45. (doi:10.1016/S0167-0115(02)00157-X)

Hauge M, Vestmar MA, Husted AS, Ekberg JP, Wright MJ, Di SJ, Weinglass AB, Engelstoft MS, Madsen AN, Luckmann M et al. 2014 GPR40 (FFAR1) - combined Gs and Gq signaling in vitro is associated with robust incretin secretagogue action ex vivo and in vivo. Molecular Metabolism 4 3-14. (doi:10.1016/j.molmet.2014.10.002)

Knop FK, Vilsboll T, Larsen S, Hojberg PV, Volund A, Madsbad S, Holst JJ \& Krarup T 2007 Increased postprandial responses of GLP1 and GIP in patients with chronic pancreatitis and steatorrhea following pancreatic enzyme substitution. American Journal of Physiology. Endocrinology and Metabolism 292 E324-E330. (doi:10.1152/ajpendo.00059.2006)

Lindgren O, Carr RD, Deacon CF, Holst JJ, Pacini G, Mari A \& Ahren B 2011 Incretin hormone and insulin responses to oral versus intravenous lipid administration in humans. Journal of Clinical Endocrinology and Metabolism 96 2519-2524. (doi:10.1210/jc.2011-0266)

Mortensen K, Christensen LL, Holst JJ \& Orskov C 2003 GLP1 and GIP are colocalized in a subset of endocrine cells in the small intestine. Regulatory Peptides 114 189-196. (doi:10.1016/S0167-0115(03)00125-3)

Moss CE, Marsh WJ, Parker HE, Ogunnowo-Bada E, Riches CH, Habib AM, Evans ML, Gribble FM \& Reimann F 2012 Somatostatin receptor 5 and cannabinoid receptor 1 activation inhibit secretion of glucosedependent insulinotropic polypeptide from intestinal $\mathrm{K}$ cells in rodents. Diabetologia 55 3094-3103. (doi:10.1007/s00125-012-2663-5)

Orskov C, Rabenhoj L, Wettergren A, Kofod H \& Holst JJ 1994 Tissue and plasma concentrations of amidated and glycine-extended glucagon-like peptide I in humans. Diabetes 43 535-539. (doi:10.2337/diab. 43.4.535)

Panaro BL, Tough IR, Engelstoft MS, Matthews RT, Digby GJ, Moller CL, Svendsen B, Gribble F, Reimann F, Holst JJ et al. 2014 The melanocortin-4 receptor is expressed in enteroendocrine $\mathrm{L}$ cells and regulates the release of peptide YY and glucagon-like peptide 1 in vivo. Cell Metabolism 20 1018-1029. (doi:10.1016/j.cmet.2014.10.004)

Parker HE, Habib A, Rogers G, Gribble F \& Reimann F 2009 Nutrientdependent secretion of glucose-dependent insulinotropic polypeptide from primary murine K cells. Diabetologia 52 289-298. (doi:10.1007/ s00125-008-1202-x)

Parker HE, Adriaenssens A, Rogers G, Richards P, Koepsell H, Reimann F \& Gribble FM 2012 Predominant role of active versus facilitative

Published by Bioscientifica Ltd. 
glucose transport for glucagon-like peptide-1 secretion. Diabetologia 55 2445-2455. (doi:10.1007/s00125-012-2585-2)

Pedersen J, Ugleholdt RK, Jorgensen SM, Windelov JA, Grunddal KV, Schwartz TW, Fuchtbauer EM, Poulsen SS, Holst PJ \& Holst JJ 2013 Glucose metabolism is altered after loss of $\mathrm{L}$ cells and alpha-cells but not influenced by loss of K cells. American Journal of Physiology. Endocrinology and Metabolism 304 E60-E73. (doi:10.1152/ajpendo.00547.2011)

Plaisancie P, Bernard C, Chayvialle JA \& Cuber JC 1994 Regulation of glucagon-like peptide-1-(7-36) amide secretion by intestinal neurotransmitters and hormones in the isolated vascularly perfused rat colon. Endocrinology 135 2398-2403. (doi:10.1210/endo.135.6. 7988423)

Reimann F, Habib AM, Tolhurst G, Parker HE, Rogers GJ \& Gribble FM 2008 Glucose sensing in L cells: a primary cell study. Cell Metabolism $\mathbf{8}$ 532-539. (doi:10.1016/j.cmet.2008.11.002)

Rocca AS \& Brubaker PL 1999 Role of the vagus nerve in mediating proximal nutrient-induced glucagon-like peptide-1 secretion. Endocrinology 140 1687-1694. (doi:10.1210/endo.140.4.6643)

Simpson AK, Ward PS, Wong KY, Collord GJ, Habib AM, Reimann F \& Gribble FM 2007 Cyclic AMP triggers glucagon-like peptide-1 secretion from the GLUTag enteroendocrine cell line. Diabetologia 50 2181-2189. (doi:10.1007/s00125-007-0750-9)

Sjolund K, Sanden G, Hakanson R \& Sundler F 1983 Endocrine cells in human intestine: an immunocytochemical study. Gastroenterology $\mathbf{8 5}$ 1120-1130. (doi:10.1016/S0016-5085(83)80080-8)

Snow ND, Prpic V, Mangel AW, Sharara AI, McVey DC, Hurst LJ, Vigna SR \& Liddle RA 1994 Regulation of cholecystokinin secretion by bombesin in STC-1 cells. American Journal of Physiology 267 G859-G865.

Svendsen B, Pedersen J, Albrechtsen NJ, Hartmann B, Torang S, Rehfeld JF, Poulsen SS \& Holst JJ 2015 An analysis of cosecretion and coexpression of gut hormones from male rat proximal and distal small intestine. Endocrinology 156 847-857. (doi:10.1210/en.2014-1710)

Sykaras AG, Demenis C, Cheng L, Pisitkun T, Mclaughlin JT, Fenton RA \& Smith CP 2014 Duodenal CCK cells from male mice express multiple hormones including ghrelin. Endocrinology 155 3339-3351. (doi:10.1210/en.2013-2165)

Theodorakis MJ, Carlson O, Michopoulos S, Doyle ME, Juhaszova M, Petraki K \& Egan JM 2006 Human duodenal enteroendocrine cells: source of both incretin peptides, GLP1 and GIP. American Journal of Physiology. Endocrinology and Metabolism 290 E550-E559. (doi:10.1152/ ajpendo.00326.2004)

Received in final form 23 September 2015

Accepted 19 October 2015

Accepted Preprint published online 19 October 2015
() 2016 Society for Endocrinology Printed in Great Britain
Published by Bioscientifica Ltd. 